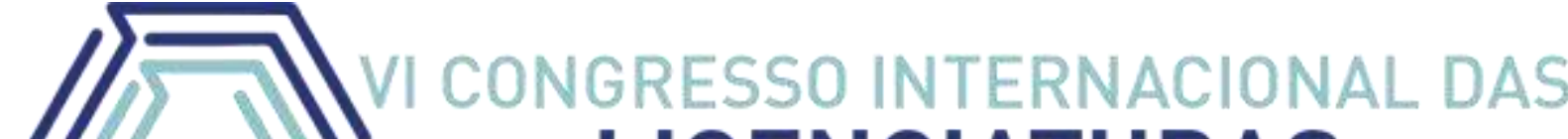 LICENCIATURAS COINTER - PDVL 2019
}

\section{AS CONTRIBUIÇÕES DO ENSINO DA DANÇA CRIATIVA PARA EDUCANDO COM SINTOMAS DEPRESSIVOS}

\section{LAS CONTRIBUCIONES DE LA ENSEÑANZA DE LA DANZA CREATIVA A LA EDUCACIÓN CON LOS SÍNTOMAS DEPRESIVOS}

\section{THE CONTRIBUTIONS OF THE TEACHING OF CREATIVE DANCE TO EDUCATING WITH DEPRESSIVE SYMPTOMS}

\author{
Apresentação: Comunicação Oral \\ Cleverson Soares de Vasconcelos ${ }^{1}$; Lívia Maria de Lima Leoncio²; Flávio Campos de \\ Moraes $^{3}$
}

DOI: https://doi.org/10.31692/2358-9728.VICOINTERPDVL.2019.0157

\section{Resumo}

A Dança é energia vital, é recriação, é a possibilidade de ser e exercitar a própria totalidade e, por isso, é potencialmente terapêutica. A Dança Criativa parte do princípio de que o estado emocional e a personalidade da pessoa estão refletidos em seus movimentos e que, portanto, se houver uma modificação nos padrões de movimento, isto refletirá em uma transformação na saúde emocional e física do indivíduo. Ela foi criada pelo bailarino e professor Rudolf Laban, que através de várias pesquisas desenvolveu uma nova forma de dançar, na qual o dançarino se expresse de forma genuína, trazendo à tona seus desejos e sentimentos íntimos, e assim externalizando em forma de movimentos ritmados. $\mathrm{O}$ presente artigo, de metodologia bibliográfica, buscou mostrar a dança como conteúdo da educação física, avaliando seus efeitos como forma de terapia em alunos com sintomas de depressão e mostrando como ela teve impactos positivos em todos os estudos e trazendo grandes benefícios para a saúde mental dos mesmos. Assim a Dança Criativa mostra-se um ótimo recuso para a melhoria da saúde metal dos alunos, pois busca auxiliar a pessoa a se conhecer, a modificar a si mesma de forma fluida, sem nenhuma opressão externa ou formal. Dessa forma, é um instrumento que

\footnotetext{
${ }^{1}$ Licenciatura em Educação Física, Universidade Federal de Pernambuco, cleversonsvpsi@gmail.com

${ }^{2}$ Licenciatura em Educação Física, Universidade Federal de Pernambuco, livia.Imll19@gmail.com

${ }^{3}$ Mestre pela UFPE, Universidade Federal de Pernambuco, flavio camposmorais@hotmail.com
} 
se adapta aos limites e às possibilidades de cada educando. Por fim, entende-se que qualquer pessoa, independentemente de suas limitações, mas principalmente através da sua parte sã, pode descobrir novas possibilidades criativas de se comunicar, movimentar e dançar através da sua forma subjetiva de ver e sentir o mundo ele que ele está inserido.

Palavras-Chave: Dança, depressão, movimento, educação.

\section{Resumen}

La danza es energía vital, es recreación, es la posibilidad de ser y ejercer su totalidad y, por lo tanto, es potencialmente terapéutica. La danza creativa supone que el estado emocional y la personalidad de la persona se reflejan en sus movimientos y que, por lo tanto, si hay un cambio en los patrones de movimiento, esto se reflejará en una transformación en la salud emocional y física de individual. Fue creado por el bailarín y profesor Rudolf Laban, quien a través de varias investigaciones desarrolló una nueva forma de baile, en la que el bailarín se expresa de una manera genuina, poniendo en el frente sus deseos y sentimientos íntimos, y por lo tanto externalizando en forma de Movimientos rítmicos. Este artículo, de metodología bibliográfica, buscaba mostrar la danza como contenido de la educación física, evaluando sus efectos como una forma de terapia en estudiantes con síntomas de depresión y mostrando cómo tuvo impactos positivos en todos los estudios y trayendo Grandes beneficios para su salud mental. Así, la danza creativa muestra un gran declive para la mejora de la salud del metal de los estudiantes, ya que busca ayudar a la persona a conocerse a sí misma, a modificarse de una manera fluida, sin ninguna opresión externa o formal. De esta forma, se trata de un instrumento que se adapta a los límites y posibilidades de cada alumno. Finalmente, se entiende que cualquier persona, independientemente de sus limitaciones, pero principalmente a través de su parte sensata, puede descubrir nuevas posibilidades creativas de comunicarse, moverse y bailar a través de su forma subjetiva de ver y sentir el mundo que que se inserta.

Palabras clave: Danza, depresión, movimiento, educación. 


\begin{abstract}
Dance is vital energy, it is re-creation, it is the possibility of being and exercising its totality and, therefore, it is potentially therapeutic. The creative dance assumes that the emotional state and personality of the person are reflected in their movements and that, therefore, if there is a change in the patterns of movement, this will reflect in a transformation in the emotional and physical health of Individual. It was created by the dancer and Professor Rudolf Laban, who through several researches developed a new form of dancing, in which the dancer expresses himself in a genuine way, bringing to the fore his desires and intimate feelings, and thus externalizing in the form of Rhythmic movements. This article, of bibliographic methodology, sought to show the dance as content of physical education, evaluating its effects as a form of therapy in students with symptoms of depression and showing how it had positive impacts in all studies and bringing Great benefits to their mental health. Thus, creative dance shows a great decline for the improvement of the students ' metal health, as it seeks to help the person to know himself, to modify himself in a fluid way, without any external or formal oppression. In this way, it is an instrument that adapts to the limits and possibilities of each student. Finally, it is understood that any person, regardless of their limitations, but mainly through their sane part, can discover new creative possibilities of communicating, moving and dancing through their subjective way of seeing and feeling the world he that it is inserted.
\end{abstract}

Keywords: Dance, depression, movement, education.

\title{
Introdução
}

Pensar em um trabalho sobre dança nas aulas de educação física é também um processo de pensar que o corpo pode levar a cura. Ao dançar o homem externaliza seus sentimentos e emoções.

Imerso em assuntos psicológicos que tratam do bem-estar, satisfação com a imagem corporal e a importância da autoimagem na vida das pessoas, acabo de tratar nesse artigo o 
corpo que dança para curar. Dessa forma a dança e a educação física, juntos com a psicologia se transforma em Dança Criativa, sobre a luz das ideias de Rudolf Laban, que ao realizar suas pesquisas no início do século $\mathrm{XX}$, referentes aos princípios gerais que regiam o movimento e suas possibilidades do homem de se comunicar e expressar seus anseios e intenções, deixounos um enorme legado para pensarmos sobre o mover-se na dança, o que nos pode dizer o corpo quando se move, quando imprime determinadas intensidades a esse mover-se, quando cria uma espacialidade em que a dança toma acontecimento.

Dessa forma, podemos dizer que as ideias de Rudolf Laban em torno de uma defesa por uma não padronização dos corpos, foram bastante revolucionárias para a sua época, o que nos oferece subsídios para refletirmos sobre o educar na dança e para além dela, tornando que dança empoderado, com autoestima e autoconhecimento para uma significativa reestruturação psicológica.

\section{Fundamentação Teórica}

\section{Depressão: Uma doença da pós modernidade?}

A história do conceito de depressão tal como o conhecemos na atualidade tem seu início no século XVII, sua origem pode ser inferida a partir das menções de alterações de humor ao longo da história, sobretudo nas referências ao estado conhecido como melancolia. (GONÇALES; MACHADO, 2013).

As primeiras descrições de estados de alteração do humor podem ser encontradas nas escrituras bíblicas e na mitologia. Hipócrates desenvolveu seu entendimento das doenças como manifestação de um desequilíbrio entre fluidos: bile, fleugma, sangue e bile negra e seu modelo dos quatro humores: colérico, fleugmático, sanguíneo e melancólico, que, segundo ele, explicariam a regulação das emoções e a formação do caráter dos indivíduos. Na visão dele o quadro clínico da melancolia em que se observava aversão à comida, falta de ânimo, inquietação, irritabilidade, medo ou tristeza que perduravam por longo período seria resultante de uma intoxicação do cérebro pela bile negra. Posteriormente Aristóteles corrobora o modelo proposto por Hipócrates e acrescenta que, enquanto o excesso de bile negra resulta em estados graves de doença mental, uma quantidade menor ou um desequilíbrio menos acentuado resulta em um temperamento melancólico. (GONÇALES; MACHADO, 2013). 
Destacam-se também as contribuições de Galeno, que reafirma a teoria dos quatro humores postulada por Hipócrates, associando os quatro elementos (ar, fogo, terra e água) com fluidos (bile amarela, bile negra, fleugma e sangue), qualidades (quente, úmido, frio e seco) e humores (colérico, fleugmático, sanguíneo e melancólico). Dessa forma o balanço entre os fluidos e as qualidades formaria os traços do temperamento de um indivíduo e as suas predisposições, enquanto um desequilíbrio significativo provocaria as doenças. Galeno preferia utilizar o termo humor melancólico, ou sangue melancólico, à bile negra e sustentava que o humor, ou o sangue melancólico, poderia ocorrer em diferentes partes do corpo e, portanto, não estaria restrito ao cérebro, como postulado por Hipócrates. Ele classificou a melancolia em três tipos, com base na localização do corpo onde supostamente estaria concentrado o desequilíbrio: no cérebro, na corrente sanguínea ou no estômago. Enfatizava, ainda, que, embora cada caso tenha as suas especificidades, o medo e a falta de ânimo eram os sintomas cardinais. Na época, os tratamentos indicados eram o uso de plantas medicinais como heléboro, meimendro, mandrágora e beladona, e de purgantes para a eliminação da bile negra. (CORDÁS, 2002).

No início da Idade Média, o pensamento greco-romano, incluindo as suas contribuições para a ciência e para a medicina, é abandonado e substituído por uma visão religiosa edificada sobre a ubiquidade de uma entidade divina e um modelo maniqueísta. Os transtornos mentais passam a ser inseridos na demonologia da época, o monge Ionnes Cassianus introduz o termo acídia, palavra de origem grega que significa "estado de descuido", para designar estados variados de apatia, preguiça, indolência, negligência e enfraquecimento, de modo que essa palavra pode ser considerada um termo medieval para a melancolia. (CORDÁS, 2002)

São Gregório Magno (Roma, 540-604) inclui a acídia entre os sete pecados capitais, logo, sujeito à penitência. São Tomás de Aquino apesar de seu profundo moralismo, demonstrou-se mais benevolente com os melancólicos. Isso porque a vitória sobre a acídia trazia o contentamento, a maior de todas as virtudes, que expressava a união mística com Deus, e, portanto, a penitência para o pecado da acídia foi atenuada. Essa postura perdurou até 1233, quando teve início o período de Inquisição na Igreja Católica, uma época em que se condenava à morte tanto os mais proeminentes intelectuais que ousavam refutar os dogmas religiosos quanto os doentes mentais, seja por motivos heréticos, seja por motivos demonológicos. (HUMES; VIEIRA; FRÁGAS, 2016) 
Uma importante contribuição nesse período é a obra do médico árabe Ishaq Ibn Imran, intitulada Melancholia, em que se encontra uma descrição dos principais sintomas da doença, como o mutismo, a imobilidade, distúrbios do sono, agitação, desânimo, choro e risco de suicídio. Ainda na Idade Média, a freira alemã Hildegard foi pioneira ao apontar a melancolia em seus estudos sobre causas e curas para as doenças, assim como diferenças na manifestação desta entre homens e mulheres. (MACHADO, N. et al., 2009).

$\mathrm{Na}$ Idade Moderna, consagrando o início de um intenso e significativo movimento social, cultural e intelectual. A visão religiosa e maniqueísta que marcou o pensamento medieval é convertida em uma visão humanista, e a doença mental passa a ser compreendida prioritariamente a partir de uma perspectiva biológica, filosófica e psicológica. $\mathrm{Na}$ era moderna, testemunha-se o período de transição da percepção da melancolia baseada no modelo humoral galênico para a ciência moderna, na qual a alquimia é substituída pela química e os humores são substituídos por nervos. (GONÇALES; MACHADO, 2013).

Dentre as principais contribuições, sobressai-se Robert Burton, que elabora uma obra clássica, intitulada A anatomia da melancolia (1621), um dos primeiros livros de psiquiatria escritos em inglês. Nessa obra, Burton enfatiza que o quadro clínico da melancolia deve ser diferenciado da loucura, à qual hoje atribuímos o nome de mania, e aponta para o fato de que um paciente pode exibir um ou outro quadro em momentos diferentes, observação pertinente que remete ao quadro que hoje é denominado transtorno bipolar. Ele diferencia também a melancolia positiva, como fonte de sabedoria e inclinação poética, religiosa e filosófica, do estado melancólico, uma doença crônica, caracterizada por um estado de humor melancólico permanente, caracterizado pela presença de medo, sofrimento e enfado, que deixa o indivíduo pesaroso, embotado, preguiçoso, inquieto e inapto ao trabalho. Burton reconhece ainda a natureza clínica da doença e faz menção ao suicídio. (MACHADO, N. et al., 2009).

O termo melancolia e as elucubrações relacionadas perderam sua valência no panorama científico. O termo depressão, por sua vez, emergiu definitivamente e consolidouse nas décadas seguintes como entidade nosológica independente. Desde então, a edificação da teoria da depressão, fundamentada na investigação científica e na observação clínica, que sustenta as práticas médicas, tem evoluído. (HUMES; VIEIRA; FRÁGAS, 2016).

A depressão, no início do século XXI, é com algumas exceções considerada uma doença mental, catalogada na Classificação Estatística Internacional de Doenças e Problemas Relacionados com a Saúde (CID) e no Manual de Diagnóstico e Estatística das Perturbações 
Mentais (DSM). Os sintomas passam por alterações no apetite ou peso, sono e atividade psicomotora, diminuição da energia, sentimentos de desvalorização pessoal ou culpa, dificuldades em pensar, concentrar-se ou em tomar decisões, pensamentos recorrentes a propósito da morte ou ideação, planos ou tentativas suicidas - em que 4 sintomas adicionais, presentes em todos os dias num período mínimo de duas semanas consecutivas, poderão levar a um diagnóstico de depressão maior (DSM V, 2014)

Desde então, a depressão tem sido um tema muito estudado e com forte relevância. Autores contemporâneos vêm realizando estudos que trazem novidades unidas a tratamentos antigos como exercícios físicos. Um desses autores é o neuropsiquiatra Servan-Shreiber que descreve sete abordagens de tratamento natural, centradas na mente e nos mecanismos de cura do próprio cérebro para se recuperar de depressão, ansiedade e estresse. Assim acreditamos ser de vital importância o profissional da área de saúde mental conhecer quais os paradigmas em que ele se baseia no atendimento às pessoas com depressão, suas ideias e seus conceitos. Muitas vezes pode não estar consciente, mas são demonstrados em seus atos. Conhecendo a história da depressão, o profissional pode tornar esses conceitos explícitos, analisá-los e decidir-se por mantê-los no atendimento às pessoas com depressão ou transformá-los, posicionando-se com consciência.

\section{A arte educação}

A escola é um ambiente que tem como objetivo a formação do cidadão reflexivo, crítico e atuante. Paulo Freire (2008) assinala que para a educação, é imprescindível à formação de cidadãos críticos, ativos, sujeitos históricos que intervenham no processo de formação da sociedade. Por este motivo encontramos a necessidade de reflexão quanto às ações da escola, que por muitas vezes trata o ensino apenas no aspecto cognitivo, desconsiderando o aspecto emocional, e deixando de trabalhar a totalidade do aluno, que por sua vez, ocasiona possíveis lacunas no processo de desenvolvimento educacional. (FREIRE,1993).

Como contrapartida a métodos tradicionais, a arte educação mostra-se como uma alternativa para possíveis mudanças no ambiente escolar, contribuindo para formação humana do aluno, para ajudá-lo a entender de forma crítica a sociedade que o rodeia e a cultura.

A mediação da arte na comunicação apresenta algumas vantagens, entre as quais a expressão mais direta do universo emocional, pois não passa pelo crivo da racionalização que 
acompanha o discurso verbal. Além disso, com a atividade artística, facilitamos o contato do sujeito com suas questões por um viés criativo, e não apenas dando forma a determinado conteúdo subjetivo, mas também podendo configurá-lo em novos sentidos. Hoje a arteterapia não está mais restrita aos consultórios psicológicos, revelando-se um valioso instrumento para intervenções também na área escolar. (DIMENSTEIN; LIBERATO, 2009) O que se quer mostrar aqui, é a arte como é um poderoso canal de expressão da subjetividade humana, que permite ao professor e o aluno, seja ele um indivíduo, seja um grupo, acessar conteúdos emocionais e retrabalhá-los através da própria atividade artística.

Jung (1875-1961), ilustre discípulo de Freud, foi quem propriamente começou a usar a linguagem artística associada à psicoterapia. Diferentemente de Freud, que considerava a arte uma forma de sublimação das pulsões, Jung considerava a criatividade artística uma função psíquica natural e estruturante, cuja capacidade de cura estava em dar forma, em transformar conteúdos inconscientes em imagens simbólicas. Jung utilizava o desenho livre para facilitar a interação verbal com o paciente e porque acreditava "na possibilidade de o homem organizar seu caos interior utilizando-se da arte" (ANDRADE, 2000, p.52). No Brasil, a história da arteterapia nasce na primeira metade do século passado entrelaçada com a psiquiatria e influenciada tanto pela vertente psicanalítica quanto pela junguiana. Estas encontram-se representadas respectivamente nas figuras de Osório Cesar (1895-1979) e Nise da Silveira (1905-1999), psiquiatras precursores no trabalho com arte junto a pacientes em instituições de saúde mental. Ambos contribuíram para o desenvolvimento de uma outra abordagem frente à loucura, contrapondo aos métodos agressivos de contenção vigentes na época (eletrochoque, isolamento) à possibilidade de expressão da loucura e de sua eventual cura através da arte.

A discussão sobre a qualidade artística ou não dos trabalhos produzidos em arteterapia, é que a atividade expressiva se torne um instrumento à expressão e à reflexão dos sujeitos. Como atividade terapêutica, o que aqui se pretende não é propriamente fazer arte, mas sim, exercitar a criatividade, proporcionar que no fazer criativo se produzam outros modos de objetivação e de subjetivação. Desse modo, ela pode ser utilizada como recurso no contexto da clínica, da educação, da comunidade, da saúde pública, das empresas, em intervenções na área de dificuldades físicas, cognitivas, emocionais e sociais junto a indivíduos, famílias, grupos sociais, equipes de trabalho e sala de aula. Uma característica comum às terapias com arte é que, por meio da vivência expressiva, o sujeito pode dar-se conta do que de fato sente e, durante esse processo, pode verdadeiramente fazer algo que 
assim o represente e a ele faça sentido (ANDRADE, 2000). Portanto, na arte educação, o fazer artístico se constitui como mediação no processo de autoconhecimento e de (re) significação do sujeito acerca de si próprio e de sua relação com o mundo. Ao tratar com a linguagem subliminar do inconsciente, vem proporcionando alívio aqueles que dela se valem na busca pela restauração de seu equilíbrio emocional. Assim compreendemos que está terapêutica é assistência no tratamento da depressão, a qual se caracteriza principalmente por causar confusão mental e baixar o humor vital do indivíduo, debilitando para o trabalho e afastando-o do convívio social. Neste cenário a arte educação, utiliza-se de materiais e técnicas diversas, onde a aplicabilidade desses recursos resultam em atividades afetivasexpressivas, colocando-se como um eficaz agente facilitador no processo de reestruturação emocional na depressão.

\section{Dança criativa e depressão}

Em um dos ramos da arte educação se encontra a dança. A expressão do corpo foi a primeira forma de arte. Reconhecida como uma arte de execução, a dança é caracterizada pela habilidade de se utilizar o movimento de forma simbólica, gerando, assim, significados, e desenvolvendo a capacidade intelectual do homem (FREIRE, 2001). Impulsiona a sensibilidade inerente ao homem e inquire a corporeidade. Considerando corporeidade como a capacidade do corpo pensar, pensamento este que conduz um movimento para representá-lo, refletindo num movimento organizado. Assim acredita-se que o ato de dançar tenha surgido junto à capacidade humana de se locomover como um bípede. A repetição sincronizada dos gestos, de cunho naturalista, foi a primeira técnica de dança desenvolvida. Utilizava o sequenciamento gradativo e estilizado de movimentos, constituindo o termo "coreografia" demonstrada em diversos hieróglifos. As danças circulares, danças de pares e danças campestres caracterizaram o abstracionismo, o domínio da técnica corporal, tornado a dança uma exibição, um entretenimento (BOURCIER, 2001).

Estudiosos da época renascentista já estudavam as possibilidades de expressão do corpo, e hoje já é difundido o conceito de que a dança abrange atividades diversas. Dançar é celebrar a existência, e dançar com consciência cria espaço e dá ritmo às sensações, emoções e experiências pessoais diversas. Ao propor tanto o conhecimento do próprio corpo e suas potencialidades quanto à percepção e expressão do que é percebido e sentido, a dança permite 
verificar limitações, constatar sensações e emoções e descobrir novos caminhos para o bemestar.

A dança enquanto arte tem o potencial de trabalhar a capacidade de criação, imaginação, sensação e percepção, integrando o conhecimento corporal ao intelectual (MARQUES, 2010). Sendo o movimento, algo presente em todas as nossas atividades, à medida que se conhece os conteúdos corporais que compõe esses movimentos (força, estrutura e dinâmicas: leve, pesado, forte, suave, rápido, lento, grande, pequeno e outros) pode-se redimensionar atitudes, reconhecer necessidades, explorar novas percepções e transformar a qualidade da própria vida, fornecendo novos níveis de sensibilidade e consciência para o cotidiano. A expressão corporal pela dança pode servir como recurso pra intervenções que evitem um déficit na orientação espacial, que está intimamente ligada ao esquema corporal, e possibilitem uma melhor qualidade de vida. A dança, portanto, é uma expressão artística essencialmente corporal, carrega elementos que possibilitam o autoconhecimento, a expressão da criatividade e auto percepção. Proporciona o contato com próprio corpo e a reconexão da materialidade corporal com o pensamento e a racionalidade. A utilização dessa arte como instrumento de terapia na recuperação sintomática de determinadas doenças está cada vez mais frequente. Além de intervenções como meio de promoção de qualidade de vida e bem-estar.

A dança é energia vital, rios criativos que nos colocam na relação com nossas emoções na forma corpórea, concreta. A dança dá corpo às emoções. Neste sentido é terapêutica. É o uso da dança e do movimento em um processo terapêutico que promove a integração emocional, cognitiva, física e social do indivíduo. Surge do encontro da dança com a psicologia e faz parte das chamadas "psicoterapias das artes criativas". É uma abordagem que utiliza a linguagem corporal como principal meio de comunicação e busca ampliar a consciência sobre si mesmo através desta linguagem. E é um instrumento simples e poderoso que permite, através de um gesto, melhorar o próprio modo de ser e estar, física e mentalmente no mundo.

A escola é o espaço das discussões sobre direitos e deveres e reflexão da realidade. É também a dimensão social das manifestações artísticas, que constitui uma das funções importantes do ensino da Arte, como propagado nos PCNs. (DUARTE JUNIOR, 1991). Dentre as artes temos: a dança, a música, o teatro, as artes plásticas e visuais. Entretanto a 
dança, aqui entendida como arte, também faz parte do bojo de conteúdos no âmbito da Educação Física, denominada cultura corporal. (COLETIVO DE AUTORES, 1992).

Segundo os PCNS da Educação Física (1997), o que se espera é que os alunos do ensino médio tenham a oportunidade de vivenciarem o maior número de práticas corporais possíveis. Ao realizarem a construção e vivências coletivas dessas práticas, estabelecem relações individuais e sociais, tendo como pano de fundo o corpo em movimento, a socialização e a formação humana.

Pereira et al (2001) coloca que a dança é um conteúdo fundamental a ser trabalhado na escola: com ela, pode-se levar os alunos a explorarem o mundo da emoção e da imaginação, a criarem, a expressarem -se através dos movimentos. Para nossa pesquisa focaremos na dança criativa a luz das ideias de Rudolf Laban.

A dança criativa é uma prática de dança que tem foco instigar a capacidade de criação. Baseia-se na organização espacial do movimento e na sua qualidade, ritmo e dinâmica. É uma forma de comunicação através do movimento, sendo voltada para todas as idades e propõe a descoberta do corpo, do movimento e suas potencialidades. Busca desenvolver uma identificação motora, de equilíbrio, lateralidade e coordenação através de movimentos dançantes.

Nas aulas de dança criativa privilegiam-se temas básicos de movimento e suas variações, ao invés de uma série de exercícios codificados e repetitivos. O trabalho desenvolvido visa incentivar o prazer do movimento e o autoconhecimento por meio da dança.

Através de percepções sensório-motoras, o trabalho procura orientar a criança na descoberta das possibilidades corporais e na investigação da sua linguagem, devolvendo a consciência, a criatividade e a expressividade do corpo. Assim, ela adquire maior controle dos seus movimentos, passando a ter maior autonomia para explorar o mundo que a rodeia.

A dança criativa atua de forma descontraída, para que cada aluno dance livremente dentro de uma proposta e se sinta capaz de ajudar na construção de uma coreografia. Ela estimula a criatividade e auto expressão, ao proporcionar uma atmosfera amigável, informativa e aberta, criando um ambiente de aprendizagem positivo, onde todos estão para compartilhar experiências corporais, sem competitividade e julgamento do certo ou errado. Além disso, ela pode melhorar o desenvolvimento social através dos jogos lúdicos imaginativos e das atividades cooperativas. 
Mas além de estimular a criatividade e facilitar a descoberta de novas formas de ações no mundo, praticar dança criativa na infância como forma de aprendizagem é sinônimo da construção de seres mais ativos e criativos na vida adulta

Através da dança podemos dizer que os exercícios físicos trazem benefícios para a pessoa com depressão maior. A depressão sendo um problema psicológico que drena grande parte da energia, impede que a pessoa tenha força de vontade para realizar as tarefas do seu dia-a-dia. A mais simples das atividades como ir ao supermercado, limpar o quintal, ou fazer exercício pode tornar-se assustadora. A perda de energia é uma das principais características da depressão. Desta forma a prática do exercício físico é uma das melhores maneiras das pessoas deprimidas melhorarem o seu humor. Podendo parecer paradoxal, mas a prática do exercício físico gera energia. Na grande maioria das vezes os sentimentos depressivos estão associados à sensação de stress, o que leva algumas pessoas a refugiarem-se e a aliviando a sua ansiedade no excesso de comida. O que conduz a um ciclo vicioso tremendamente negativo. Isto porque a pessoa fica propensa a uma alteração da sua autoimagem e consequentemente é afetada na sua autoestima.

Quando se propõe a movimentar-se e a fazer exercício, ocorre um estado de excitação geral do corpo. Esta ativação geral, inclui diversos sistemas do corpo. Desde a ativação do metabolismo cardiovascular, vários tipos de alterações endócrinas no cérebro, vários tipos de alterações hormonais e mudanças fisiológicas acontecem um pouco por todo o organismo. Este tipo de mobilização do corpo faz com que existam igualmente algumas alterações no nosso cérebro, contribuindo para alterações positivas nos estados de humor. Tem efeitos positivos em alguns neurotransmissores tal com alguns medicamentos antidepressivos. Dessa forma, os exercícios físicos produzem substâncias químicas no cérebro, chamadas de "endorfinas", que promovem a sensação de bem-estar e satisfação, e a liberta da tensão nos músculos. A tensão muscular contribui para a dor relacionados com a depressão e insónia. Reduz os níveis hormonais do stress, como o cortisol, aliviando os sentimentos de ansiedade e agitação e aumenta a temperatura do corpo, promovendo a sensação de relaxamento, produzindo efeitos calmantes. (MORAES. et al., 2007).

\section{Metodologia}

Esta pesquisa tem como objetivo, explicar e construir hipóteses sobre quais são as contribuições do ensino da dança criativa para a saúde mental de escolares com sintomas 
depressivos, aprimorando as ideias, e fundamentando o assunto em questão. Para tanto, esse trabalho foi elaborado a partir de uma revisão bibliográfica da literatura nas bases de dados Lilacs, PubMed e Scielo, no período entre 2000 e 2019, como também, foram utilizados alguns livros que são referência sobre a Dança Criativa.

As palavras-chave utilizadas foram "dança", "depressão" e "educação" e suas correspondentes em inglês, "dance", "depression" e "education". Somando-se todas as bases de dados, foram encontrados 460 artigos. Foram critérios de exclusão: artigos publicados antes de 2000, artigos com repetição nas diferentes bases e que não preenchiam os objetivos deste estudo de acordo com seus títulos. Foram selecionados 50 artigos para a leitura do resumo, dos quais 17 tiveram relação com o ensino da dança criativa para educandos com sintomas depressivos que foram lidos na íntegra.

Sobre os resultados, percebemos a escassez de publicações a respeito do tema pesquisado, além de novas abordagens que mostrem a dança não só como conteúdo da Educação Física, mas também em estudos que apontem as contribuições positivas que ela trás para saúde mental de escolares.

\section{Resultados e Discussão}

Diante dos resultados obtidos, o ensino da dança criativa nas aulas de educação física "traz à consciência as particularidades da expressão humana, os traços da personalidade, a harmonização pessoal e social, assim como a consciência dos esforços e do corpo no espaço" (MARQUES, 2010, p. 74). Dessa forma, podemos afirmar que são várias as pistas que esse estudioso nos concede acerca de uma proposição que integra arte e educação. Tanto ressalta a importância de o aprendiz se apropriar de conceitos específicos de dança (como o aprendizado dos fluxos de movimento, por exemplo), como também evidencia a importância de se educar a pessoa para a vida, buscando sua harmonia e transformação na sua relação com a dança e com a sociedade em que se insere.

No que se refere aos escolares, os autores trazem que esses princípios os estimulam a empregar suas próprias ideias e provocam o descondicionamento de convenções e normatizações impostas pelas danças normatizadas. Para o professor de dança, por exemplo, Laban (1990) orientava uma forma de proceder na qual ele estimulasse a buscasse complementar os impulsos e a ampliação das ações dos seus alunos. Convocando no educador uma atitude menos diretiva e mais mobilizadora em torno da criação de situações de 
aprendizagem em que os aprendizes terão mais liberdade e autonomia para lançar-se nas suas descobertas, observarem os colegas e assumirem a responsabilidade das suas decisões.

A partir disso, entende-se que através da dança os alunos tem uma abertura de canais que eles possam externalizar sua subjetividade e assim aprender com suas atitudes, formas novas de lidar com seus sentimentos, tendo em vista que eles mesmos são os criadores de suas coreografias e não há opressões externas durante suas expressões, tornando única e genuína a sua forma de dançar.

\section{Conclusões}

Em meados da década de 20, a dança foi utilizada como terapia física. Dessa forma é definida como um composto ritmado de movimentos e gestos que engloba aspectos físicos, emocionais e cognitivos. A dança se desenvolveu a partir de expressões primitivas estando presente em diferentes contextos culturais, como divertimentos, manifestação artística ou parte de cerimônias e rituais. Por sua origem e conceito, a dança é comumente investigada através da ótica psicossocial e pedagógica, entretanto, o envolvimento físico da pessoa que dança é o que caracteriza a dança como uma forma de exercício físico.

A dança criativa é um tipo de dança que veio para tirar a ideia de movimentos funcionais, e aplicar os desejos e movimentos pessoais de quem está dançando, ou seja, é uma dança que expressa emoções e sentimentos pessoais. Sendo assim uma dança muito indicada para ser trabalhada na escola, pois permite os alunos a lidar com os problemas e as prepara para a vida e não somente para uma apresentação bonita e "engessada" como nas danças tradicionais.

A dança criativa surgiu dos estudos de Rudolf Laban, que fez várias pesquisas sobre movimentos corporais para que a dança pudesse ter novos movimentos sem perder sua qualidade e dinâmica, isso da aos alunos uma identificação pessoal, além de sempre estar estimulando a criatividade. Tudo isso faz com que os dançarinos consigam ser preparadas para o dia a dia, pois a harmonia da dança também traz harmonia para a vida.

Pode-se, de forma geral, dizer que a dança funciona como uma terapia complementar a outros tratamentos para a depressão. Pois a depressão é um transtorno sério, acompanhado por sentimentos de desesperança. Porém, estes sentimentos mostram-se ambíguos e intercalados por momentos de lucidez e esperança em relação a vida e ao futuro. Assim, a dança se dá além dos tratamentos principais. Tendo em vista que ela melhora emoções, funções 
cognitivas, percepção corporal, atividade, funcionalidade na vida e questões subjetivas em relação a esperança, projetos de vida, percepção de produtividade e capacidade, a pessoa com depressão pode obter benefícios a partir do envolvimento em aulas de dança regulares, e principalmente nas aulas de dança criativa.

\section{Referências}

ABRÃO, Ana Carla Peto; PEDRÃO, Luiz Jorge. A contribuição da dança do ventre para a educação corporal, saúde física e mental de mulheres que freqüentam uma academia de ginástica e dança. Revista Latino-Americana de Enfermagem, v. 13, n. 2, p. 243-248, 2005.

ALBRIGHT, Ann Cooper (Ed.). Taken by surprise: A dance improvisation reader. Wesleyan University Press, 2003.

ANDRADE, L. Q. Terapias Expressivas: arte-terapia, arte-educação, terapia. São Paulo: Vector, 2000.

ANDRADE, T. R. O exercício físico no tratamento da depressão: uma revisão de literatura. 2011. 32 f. Trabalho de Conclusão de Curso (Bacharel e Licenciado em Educação Física)-Faculdade de Educação Física, Universidade Estadual de Campinas, Campinas, 2011.

AMERICAN PSYCHIATRIC ASSOCIATION. DSM-5: manual diagnóstico e estatístico de transtornos mentais. Porto Alegre: Artmed, 2014.

BOURCIER, P. História da dança no Ocidente. São Paulo: Martins Fontes, 2001.

CERRUTO, E. Dançaterapia: "Como?". Centro de Formação Internacional de dançaterapia - DMT, 2007. Disponível em: http://www.dancaterapiadmt.com.br/artigos/Dan\%E7aterapia\%20como!!!.pdf. Acesso em: 07 outubro. 2019.

COLETIVO DE AUTORES. Metodologia do Ensino da Educação Física. São Paulo: Cortez, 1992. Coleção Magistério $2^{\circ}$ grau - série formação do professor.

CORDÁS, T. A. Depressão: da bile negra aos neurotransmissores. Uma introdução histórica. São Paulo-SP: Lemos Editorial, 2002.

DIMENSTEIN, M.; LIBERATO, M. Desinstitucionalizar é ultrapassar fronteiras sanitárias: o desafio da intersetorialidade e do trabalho em rede. Cadernos Brasileiros de Saúde Mental, Florianópolis, v. 1, n. 1, p. 212-222, 2009.

DUAILIBI, K.; SILVA, A. S. M.; JUBARA, C. F. B. Como diagnosticar e tratar depressão. Copyright Moreira Jr. Editora, v 71, n 12, p 23-31, Dez. 2014. 
DUARTE JÚNIOR, João Francisco. Porque Arte-Educação? 6. ed. - Campinas, SP: Papirus, 1991;

FERNANDES, A. D. A dança como forma de terapia em populações brasileiras: um estudo de revisão. 2015. 35 f. Trabalho de Conclusão de Curso (Licenciado em Dança)-Escola de Educação Física, Universidade Federal do Rio Grande do Sul. Porto Alegre, 2015.

FREIRE, I. Dança-Educação: O Corpo e o Movimento do Espaço do Conhecimento. Caderno Sedes, 21 (53), 31-55, 2001.

FREIRE, P. Política e educação. Indaiatuba: Villa das Letras Editora, 1993.

FREIRE, P. Conscientização: Teoria e prática da libertação. Uma introdução ao pensamento de Paulo Freire. São Paulo: Centauro, 2008.

FUX, M. Dançaterapia. São Paulo: Summus: 1988.

GONÇALES, C. A. V.; MACHADO, A. L. Depressão, o mal do século: de que século? In: QUEVEDO, J. SILVA, A.G. (Org.) Depressão: teoria e clínica. Porto Alegre: Artmed, 2013.

HUMES, E. C.; VIEIRA. M. E.B.; FRÁGAS, R. Psiquiatria Interdisciplinar. Baureli, SP: Manole, 2016.

Laban, R. Dança educativa moderna. São Paulo: Ícone, 1990.

MACHADO, N. et al. Transtorno depressivo maior: avaliação da aptidão motora e da atenção. J Bras Psiquiatria. 58(3), p. 175-180. 2009.

MARQUES, I. A linguagem da dança: arte e ensino. São Paulo: Digitexto, 2010.

MORAES, et al. Exercício físico no tratamento da depressão em idosos. Revista de Psiquiatria, Rio Grande do Sul. 29(1):70-79, 2007.

NANNI, D. Dança educação, princípios métodos e técnicas. 2.ed. Rio de Janeiro: SPRINT, 1998.

PARÂMETROS CURRICULARES NACIONAIS: EDUCAÇÃO FÍSICA/SECRETARIA DE EDUCAÇÃO FUNDAMENTAL. - Brasília: MEC/SEF, 1997. Disponível em: <http://portal.mec.gov.br/component/content/article?id=12640:parametros-curricularesnacionais-10-a-4o-series>. Acesso em: 28 ago. 2019.

PAXTON, Steve. Transcription. Contact quarterly. Northampton, MA, v.11, n.1, p.48-50, Winter 1986. 
PEREIRA, S. R. C. et al., Dança na escola: desenvolvendo a emoção e o pensamento. Revista Kinesis, Porto Alegre, n. 25, p.60- 61,2001.

REIS, A. C. Subjetividade e experiência do corpo na Biodança. Estudos e Pesquisas em Psicologia, Rio de Janeiro, v. 13, n. 3, p. 1103-1123, 2013.

THIOLLENT, M. Metodologia da pesquisa - ação. 2. ed. São Paulo: Cortez, 1986.

VIDAL, Samuel Estevam. Efeitos da dança sobre a manutenção da estabilidade dinâmica e qualidade de vida de indivíduos com doença de Parkinson. 2014.

WIEBUSCH, Eloisa Maria. ESCOLA: ESPAÇO DE HUMANIZAÇÃO. $>$ https://www2.faccat.br/portal/sites/default/files/wiebusch.pdf<. Acesso em 29 ago. 2019. 